\title{
Lower limits of fluorescein and indocyanine green dye for digital cSLO fluorescence angiography
}

\author{
A Bindewald, O Stuhrmann, F Roth, S Schmitz-Valckenberg, H-M Helb, A Wegener, N Eter, \\ F G Holz
}

See end of article for authors' affiliations

Correspondence to:

Frank G Holz, MD,

Department of

Ophthalmology, University

of Bonn, Ernst-Abbe-

Strasse 2, D-53127 Bonn,

Germany; frank.holz@

ukb.uni-bonn.de

Accepted for publication 1 July 2005
Background: With the advent of digital confocal scanning laser ophthalmoscopy it is possible to detect low levels of fluorescence. Here we used a novel confocal scanning laser ophthalmoscope (cSLO) to determine lower limits of dye required for fluorescein (FL) and indocyanine green (ICG) angiography.

Methods: A cSLO (Heidelberg retina angiograph 2, Heidelberg Engineering, Dossenheim, Germany) with an optically pumped solid state laser $(488 \mathrm{~nm})$ for FL and a diode laser $(790 \mathrm{~nm})$ for ICG angiography (FL/ICG-A) was used. $62 \mathrm{FL}-A$ s were performed in 53 patients and 45 ICG-As were performed in 39 patients with neovascular age related macular degeneration. The volume and overall dye content of bolus injections was gradually tapered (FL: 500 mg, 250 mg, 200 mg, 166 mg, 100 mg; ICG: 25 mg, 20 mg, $15 \mathrm{mg}, 10 \mathrm{mg}, 5 \mathrm{mg}, 2.5 \mathrm{mg}$ ), while dye concentrations were kept constant at $100 \mathrm{mg} / \mathrm{ml} \mathrm{for} \mathrm{FL} \mathrm{and} \mathrm{at}$ $5 \mathrm{mg} / \mathrm{ml}$ for ICG. Images were obtained 1, 5, 15, and 30 minutes after dye injection. Image quality was evaluated by two independent readers using standardised criteria.

Results: For amounts down to $166 \mathrm{mg}$ for FL and to $5 \mathrm{mg}$ for ICG, sufficient image quality was achieved during all phases following injection. Only late phase images showed less contrast compared to typically used dye amounts, which was irrelevant for interpretation and clinical management.

Conclusions: With the increased sensitivity of this novel cSLO system, amounts of injected dye during FL-A can be reduced to one third for FL and to one fifth for ICG without relevant loss of image quality or information compared to conventionally used dye levels. These amounts can be used for routine angiography and allow relevant savings for units performing FL-A.
$\mathrm{F}$ luorescence angiography (FL-A) with fluorescein (FL) and indocyanine green (ICG) represents an important diagnostic tool for evaluation of a wide spectrum of retinal diseases. ${ }^{1-10}$ Two different imaging systems have been introduced for FL-A. Conventional fundus cameras were initially used by Nowotny and Alvis. ${ }^{11}$ As a result of the pioneering work of Webb and co-workers, scanning laser ophthalmoscopes (SLOs) have become available for routine application. ${ }^{12-14}$ Fundus camera based systems use a bank of capacitors that are discharged through a xenon flash tube for FL-A. Photographs are recorded on film or digitised via a CCD (charge coupled device) camera on a computer system. Frame rate is limited with these systems for various reasons, including time required for recharging the capacitors. With the advent of cSLO and recent further technological improvements, it is now possible to detect very low levels of fluorescence in the eye. ${ }^{15-17}$ Compared to the flash light used to illuminate the fundus of conventional fundus cameras, ${ }^{18}$ cSLOs use a laser beam with adequate wavelength for excitation of physiological or diagnostically injected fluorophores. In confocal systems, light from a confocal plane is detected while light from planes anterior and posterior to the plane of interest are suppressed. Although optical properties of the human eye still limit image resolution, cSLO angiography allows for high contrast images with a high horizontal resolution of the posterior pole of the eye. Furthermore, it is possible to record images in real time at a high frame rate and therefore to visualise detailed dynamic processes. Because fluorescein and ICG have different spectral characteristics, simultaneous angiographies can be performed using SLO systems. ${ }^{19-23}$

Given the high sensitivity of cSLO systems compared to conventional camera systems, we hypothesised that lower amounts of FL and ICG dye would be required for routine FLA. Here we determined the lower limit of dye using stepwise reduction in FL or ICG injected for FL-A using a novel cSLO.

\section{PATIENTS AND METHODS}

For consecutive FL angiography (A) and ICG-A, a novel cSLO (HRA2, Heidelberg Engineering, Dossenheim, Germany) was used. The principle of CSLO for FL-A has been described previously. ${ }^{15} 2123-25$ The HRA2 uses an optically pumped solid state laser $(488 \mathrm{~nm})$ for FL-A and a diode laser $(790 \mathrm{~nm})$ for ICG-A. Maximum retinal irradiance is approximately $2.0 \mathrm{~mW} / \mathrm{cm}^{2}$ and therefore lies below the limits established by the American National Standards Institute and other international standards. ${ }^{26}$ Emission is recorded between $500 \mathrm{~nm}$ and $700 \mathrm{~nm}$ with a detection efficiency of $85 \%$ for FL-A images, and above $810 \mathrm{~nm}$ with a detection efficiency of $66 \%$ for ICG recordings. A digital zoom at an angle of $30^{\circ}$ was used to obtain digital images of $768 \times 768$ pixels using the continuous or single image acquisition mode at a line scan frequency of $8 \mathrm{kHz}$ (maximum 16 frames per second). For digital image processing, the included software was used (Heidelberg Eye Explorer, HEE, Heidelberg Engineering, Dossenheim, Germany).

We performed 62 FL-As on 53 patients (20 male, 33 female; age 76.5 (SD 7.5) years), and 45 ICG-As on 39 patients (15 male, 24 female, age 76.1 (9.0) years) seen in the retina outpatient clinic of the department of ophthalmology, University of Bonn. The patients all had neovascular age

Abbreviations: CCD, charge coupled device; CSLO, confocal scanning laser ophthalmoscopy; FA, fluorescence angiography; FL, fluorescein; $\mathrm{FL}-\mathrm{A}$, fluorescein angiography; ICG-A, indocyanine green angiography; $I C G$, indocyanine green 

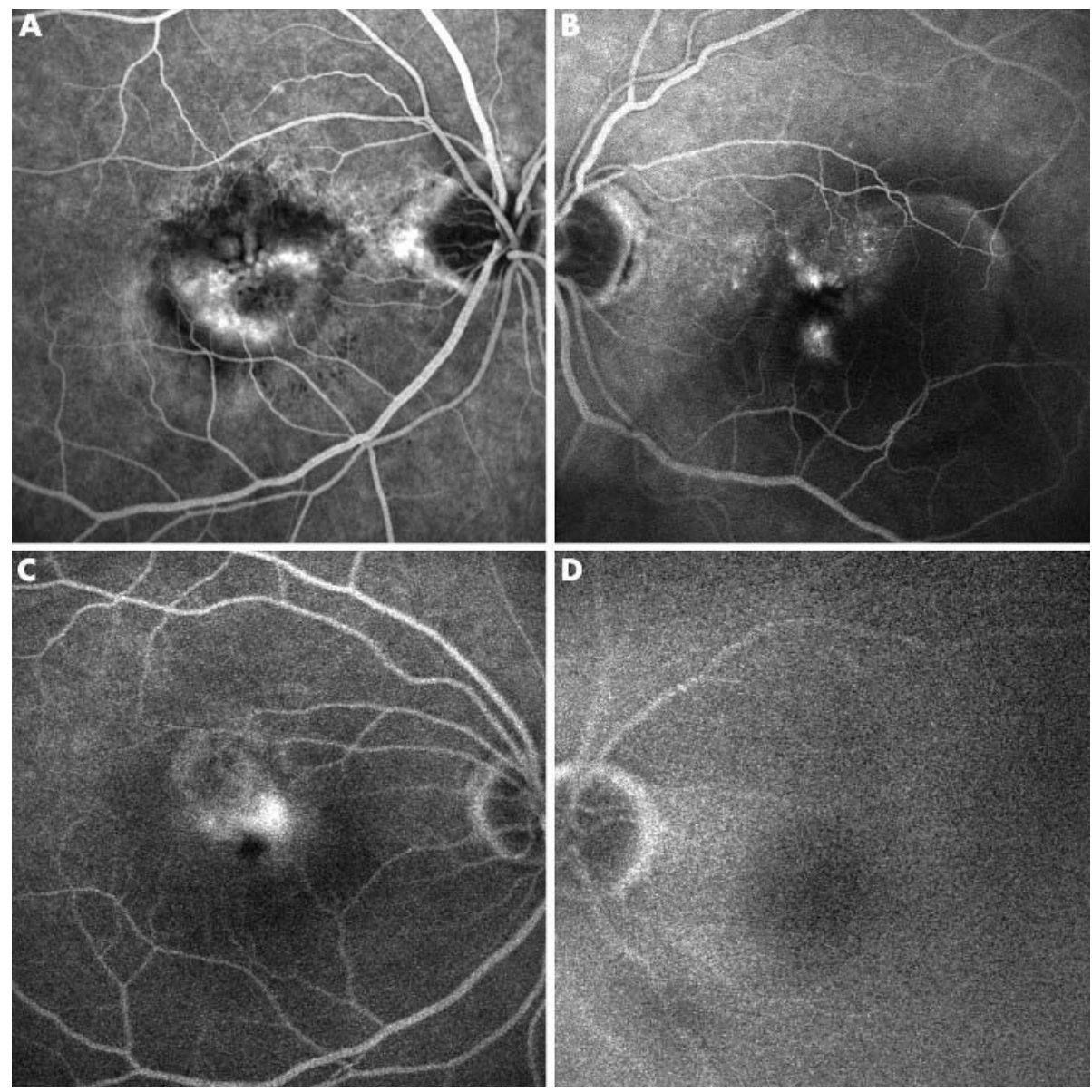

Figure 1 Grading system with four categories for fluorescence angiographies. (A) "Very good" (5 minutes), (B) "good" (5 minutes), (C) "poor image quality" (15 minutes), (D) "not readable" (15 minutes).
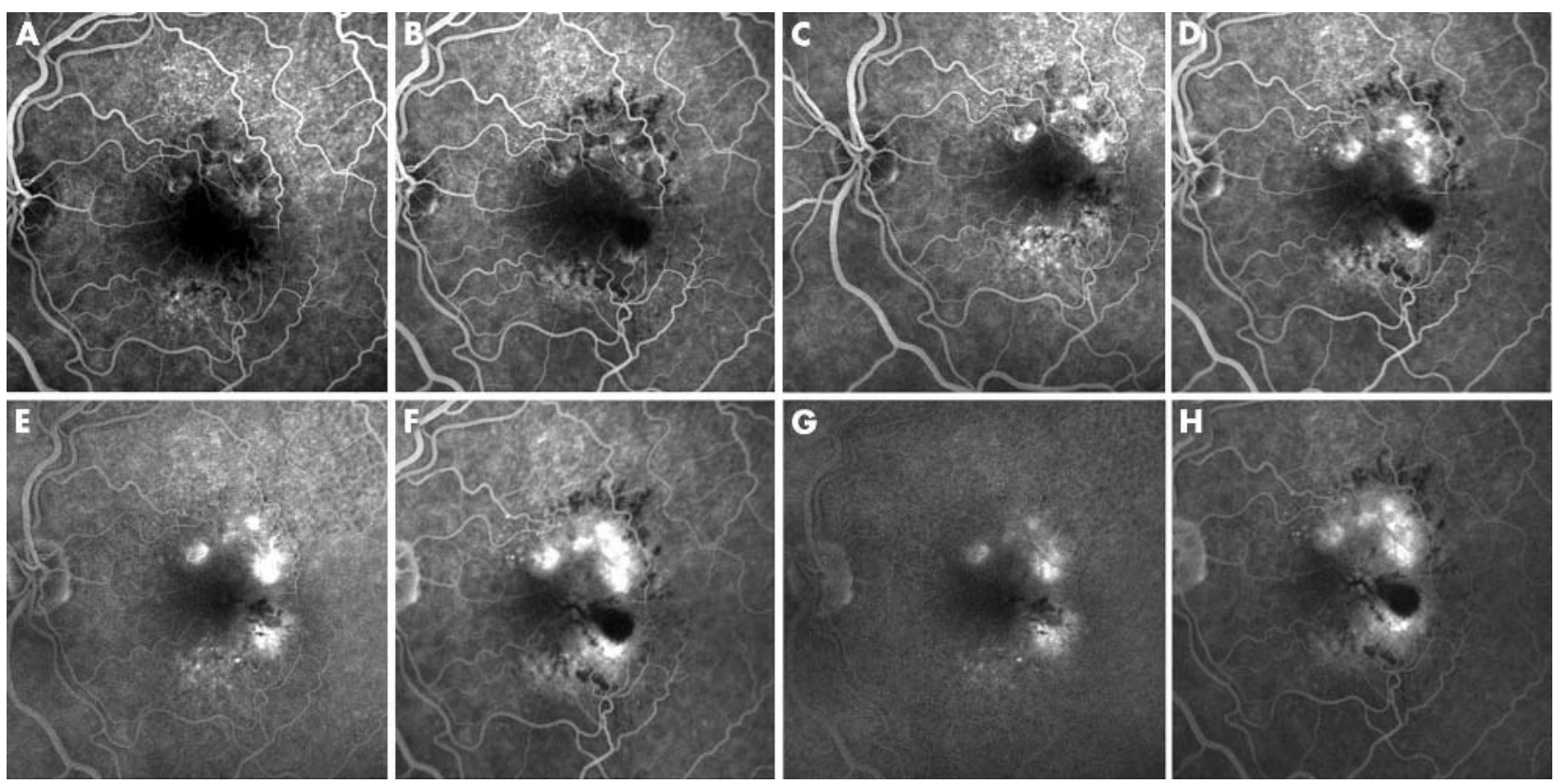

Figure 2 Fluorescein angiography of a 79 year old pseudophakic patient with neovascular age related macular degeneration. This figure shows results from injection of $500 \mathrm{mg}(B, D, F, H)$ and $166 \mathrm{mg}(A, C, E, G)$ of fluorescein dye. Note progression of disease after 6 weeks (top row) with more leakage and haemorrhage, which is independent from the amount of administered fluorescein. (A, B) 1 minute, (C, D) 5 minutes, (E, F) 15 minutes, (G, H) 30 minutes.

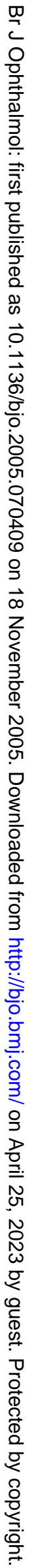



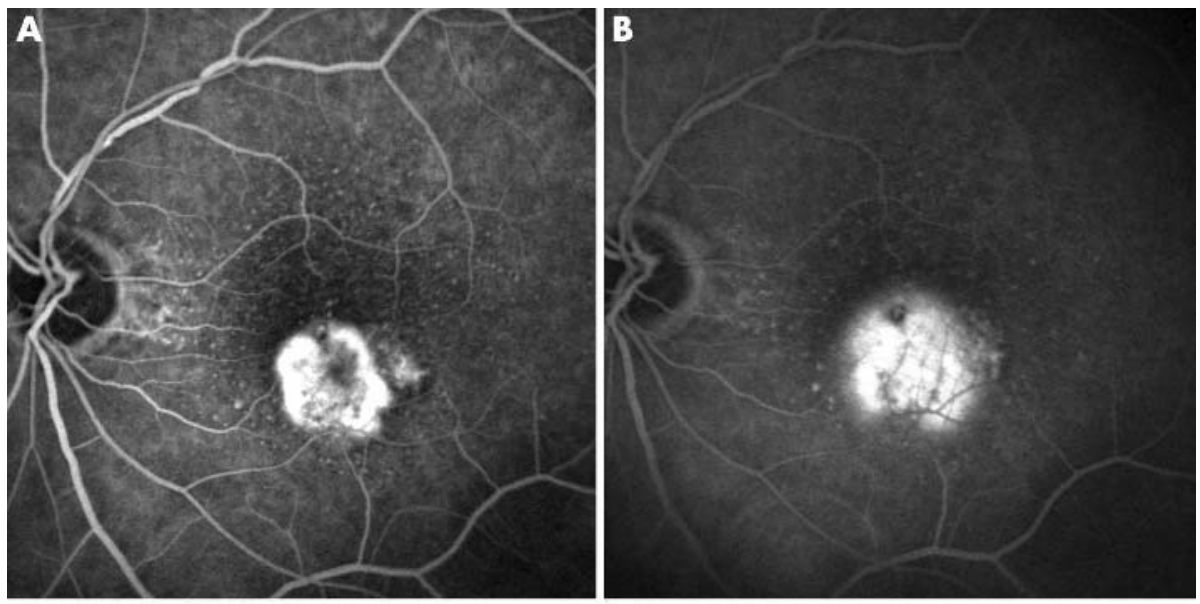

Figure 3 Fluorescein angiography of a 82 year old phakic patient using $166 \mathrm{mg}$ fluorescein. All details of the minimally classic choroidal neovascularisation can be identified during all phases of angiography. (A) 1 minute, (B) 5 minutes, (C) 15 minutes, (D) 30 minutes.
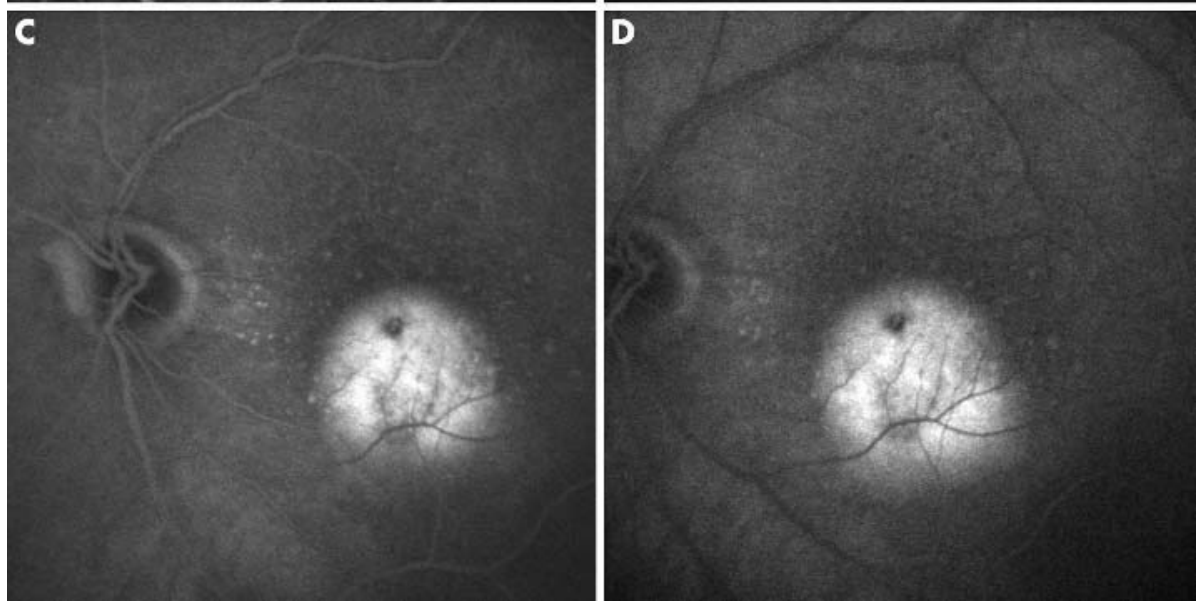

related macular degeneration (AMD). FL-As and ICG-As were performed consecutively. The volumes and dye amounts $(\mathrm{mg})$ of the bolus injections were gradually tapered for both FL $(500 \mathrm{mg}, 250 \mathrm{mg}, 200 \mathrm{mg}, 166 \mathrm{mg}, 100 \mathrm{mg}$; fluorescein 10\%, Alcon Pharma GmbH, Freiburg, Germany) and ICG (25 mg, $20 \mathrm{mg}, 15 \mathrm{mg}, 10 \mathrm{mg}, 5 \mathrm{mg}, 2.5 \mathrm{mg}$; ICG-Pulsion, Pulsion Medical Systems AG, Munich, Germany), while dye concentrations were maintained at $100 \mathrm{mg} / \mathrm{ml}$ for FL and at $5 \mathrm{mg} / \mathrm{ml}$ for ICG. Patients were randomly assigned to different volumes and dye amounts. All injections were performed by the same injecting physician in an attempt to achieve similar injection dynamics for all angiograms. In each patient, $30^{\circ}$ images were recorded at $1,5,15$, and 30 minutes after dye injection.

Inclusion criteria included media clear enough to allow satisfactory imaging, especially absence of advanced lens opacities, and informed written consent. Patients with contraindications for FL or ICG injection (for example, allergies to shellfish, penicillin, or iodine; pregnancy; known allergies to either FL or ICG; or insufficient compliance and

Table 1 Fluorescein angiographies and dye amounts used

\begin{tabular}{lll}
\hline No $(\mathbf{n}=62)$ & FL amount & FL injected volume $(100 \mathrm{mg} / \mathrm{ml})$ \\
\hline 11 & $100 \mathrm{mg}$ & $1.00 \mathrm{ml}$ \\
17 & $166 \mathrm{mg}$ & $1.66 \mathrm{ml}$ \\
10 & $200 \mathrm{mg}$ & $2.00 \mathrm{ml}$ \\
9 & $250 \mathrm{mg}$ & $2.50 \mathrm{ml}$ \\
15 & $500 \mathrm{mg}$ & $5.00 \mathrm{ml}$ \\
\hline
\end{tabular}

nystagmus) were excluded. ${ }^{27}$ The study was reviewed by the appropriate ethics committee and performed in accordance with the ethical standards laid down in the Declaration of Helsinki. ${ }^{28}$

Quality of images was evaluated by two independent readers using standardised criteria and classified as "very good," "good," "poor image quality," or "not readable" (fig 1). In case of a discrepancy, a third reader was asked to arbitrate. The readers were not aware of the dye amounts injected.

Statistical analyses were performed using commercially available software (SPSS, SPSS GmbH Software, Munich, Germany). Results at each time point of examination (1, 5, 15 , and 30 minutes) were tested for interaction of the amount of dye and image quality as quantitative variables using $\chi^{2}$ and linear by linear association tests.

\section{RESULTS}

We performed 62 FL-As in 53 patients, using an identical concentration of dye in five different bolus volumes (table 1). While 30 patients were phakic, 23 patients had undergone cataract surgery. Four images of each FL-A (at 1, 5, 15, and 30 minutes after injection) were classified into the categories as mentioned above by two independent readers. The two readers graded a total of $428 \mathrm{FL}-\mathrm{A}$ and ICG-A images. While complete agreement was achieved in $68.7 \%$ of the cases, in $30.8 \%$ there was a minor difference in grading-that is, within one step of the grading scale. During the earlier phases of FL-A ( 1 minute and 5 minutes after injection), a total of $96.7 \%$ of images after 1 minute and $85.5 \%$ of images after 5 minutes following injection were classified either as "very good" or "good," and none was classified as "not readable" 
Table 2 Results of the evaluation of fluorescein angiographies

\begin{tabular}{|c|c|c|c|c|c|}
\hline FL & Very good & Good & Poor & $\begin{array}{l}\text { Not } \\
\text { readable }\end{array}$ & No \\
\hline \multicolumn{6}{|l|}{1 minute } \\
\hline $100 \mathrm{mg}$ & $6(54.5 \%)$ & $5(45.5 \%)$ & $0(0 \%)$ & $0(0 \%)$ & 11 \\
\hline $166 \mathrm{mg}$ & $9(52.9 \%)$ & $7(41.2 \%)$ & $1(5.9 \%)$ & $0(0 \%)$ & 17 \\
\hline $200 \mathrm{mg}$ & $8(80 \%)$ & $2(20 \%)$ & $0(0 \%)$ & $0(0 \%)$ & 10 \\
\hline $250 \mathrm{mg}$ & 7 (77.8\%) & $1(11.1 \%)$ & $1(11.1 \%)$ & $0(0 \%)$ & 9 \\
\hline \multirow[t]{2}{*}{$500 \mathrm{mg}$} & $11(73.3 \%)$ & $4(26.7 \%)$ & $0(0 \%)$ & $0(0 \%)$ & 15 \\
\hline & $41(66.1 \%)$ & $19(30.6 \%)$ & $2(3.2 \%)$ & $0(0 \%)$ & 62 \\
\hline \multicolumn{6}{|c|}{5 minutes } \\
\hline $100 \mathrm{mg}$ & $3(27.3 \%)$ & $6(54.5 \%)$ & $2(18.3 \%)$ & $0(0 \%)$ & 11 \\
\hline $166 \mathrm{mg}$ & $8(47.1 \%)$ & 5 (29.4\%) & $4(23.5 \%)$ & $0(0 \%)$ & 17 \\
\hline $200 \mathrm{mg}$ & $7(70 \%)$ & $3(30 \%)$ & $0(0 \%)$ & $0(0 \%)$ & 10 \\
\hline $250 \mathrm{mg}$ & 7 (77.8\%) & $0(0 \%)$ & 2 (22.2\%) & $0(0 \%)$ & 9 \\
\hline \multirow[t]{2}{*}{$500 \mathrm{mg}$} & $10(66.7 \%)$ & $4(26.7)$ & $1(6.7 \%)$ & $0(0 \%)$ & 15 \\
\hline & $35(56.5 \%)$ & $18(29 \%)$ & $9(14.5 \%)$ & $0(0 \%)$ & 62 \\
\hline \multicolumn{6}{|c|}{15 minutes } \\
\hline $100 \mathrm{mg}$ & $0(0 \%)$ & 8 (72.7\%) & $3(27.3 \%)$ & $0(0 \%)$ & 11 \\
\hline $166 \mathrm{mg}$ & $3(17.6 \%)$ & $8(47.1 \%)$ & $5(29.4 \%)$ & $1(5.9 \%)$ & 17 \\
\hline $200 \mathrm{mg}$ & $0(0 \%)$ & $10(100 \%)$ & $0(0 \%)$ & $0(0 \%)$ & 10 \\
\hline $250 \mathrm{mg}$ & $2(22.2 \%)$ & $5(55.6 \%)$ & $2(22.2 \%)$ & $0(0 \%)$ & 9 \\
\hline \multirow{2}{*}{$500 \mathrm{mg}$} & 8 (53.3\%) & 5 (33.3\%) & $2(13.3 \%)$ & $0(0 \%)$ & 15 \\
\hline & $13(21 \%)$ & $36(58.1 \%)$ & $12(19.4 \%)$ & $1(1.6 \%)$ & 62 \\
\hline \multicolumn{6}{|c|}{30 minutes } \\
\hline $100 \mathrm{mg}$ & $0(0 \%)$ & 7 (63.6\%) & $3(27.3 \%)$ & $1(9.1 \%)$ & 11 \\
\hline $166 \mathrm{mg}$ & 1 (5.9\%) & $8(47.1 \%)$ & $6(35.3 \%)$ & $2(11.8 \%)$ & 17 \\
\hline $200 \mathrm{mg}$ & $0(0 \%)$ & $7(70 \%)$ & $1(10 \%)$ & $2(20 \%)$ & 10 \\
\hline $250 \mathrm{mg}$ & $0(0 \%)$ & 7 (77.8\%) & $0(0 \%)$ & $2(22.2 \%)$ & 9 \\
\hline \multirow[t]{2}{*}{$500 \mathrm{mg}$} & $7(46.7 \%)$ & $6(40 \%)$ & $2(13.3 \%)$ & $0(0 \%)$ & 15 \\
\hline & $8(12.9 \%)$ & $35(56.5 \%)$ & 12 (19.4\%) & $7(11.3 \%)$ & 62 \\
\hline
\end{tabular}
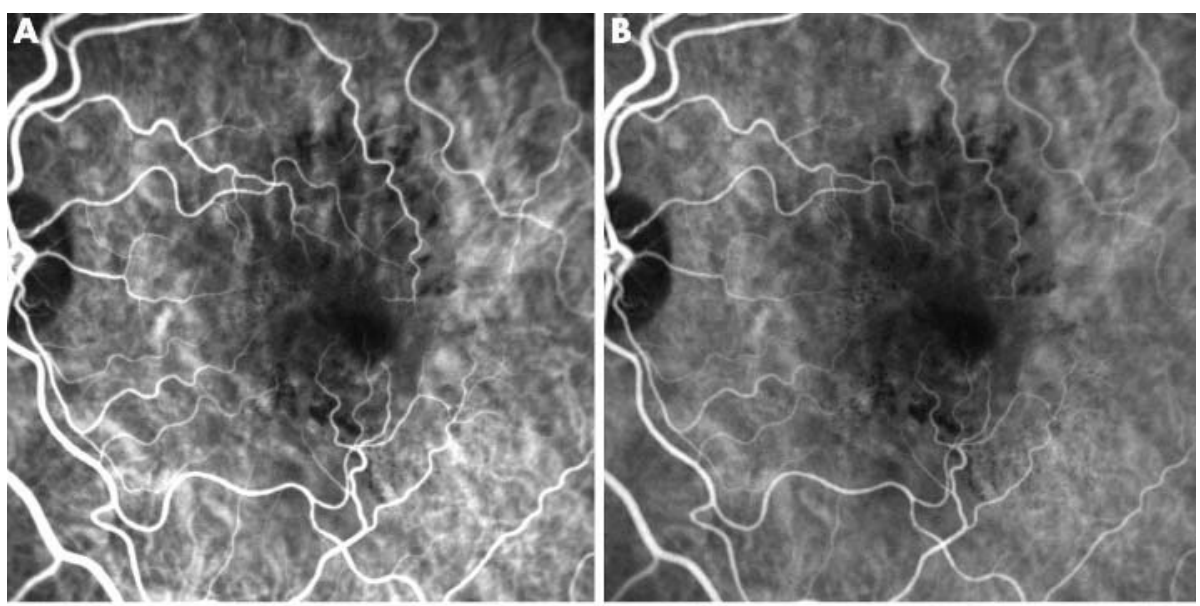

Figure 4 Indocyanine green (ICG) angiography of a 79 year old pseudophakic patient using the full amount of $25 \mathrm{mg}$ of dye. (A) 1 minute,

(B) 5 minutes, (C) 15 minutes, (D) 30 minutes.
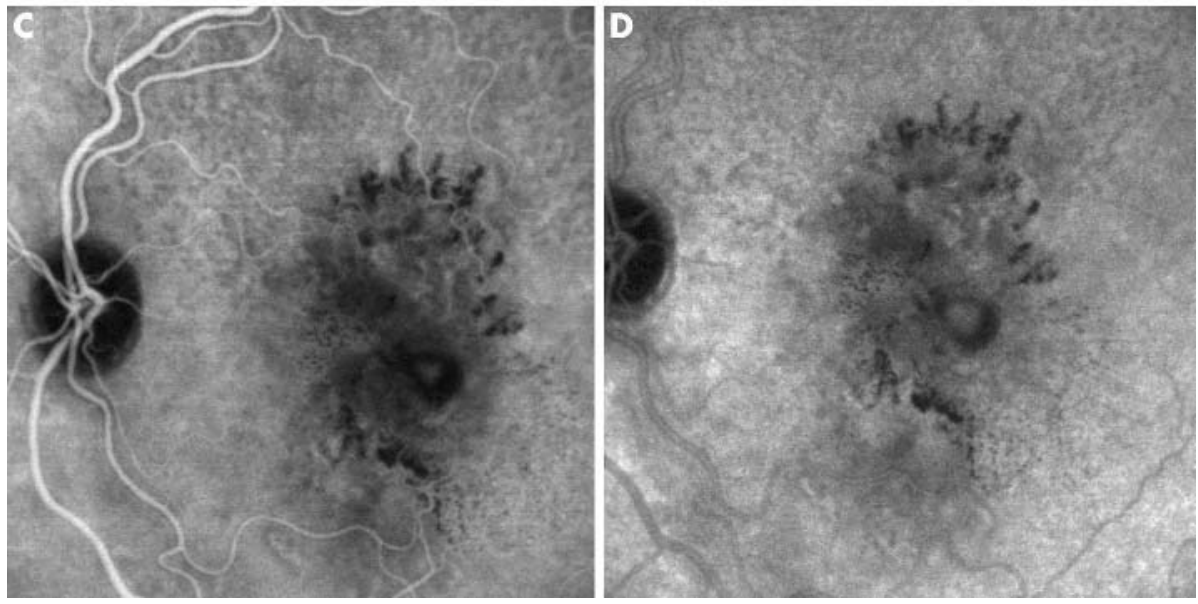

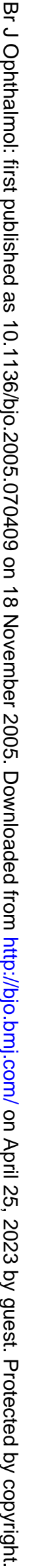



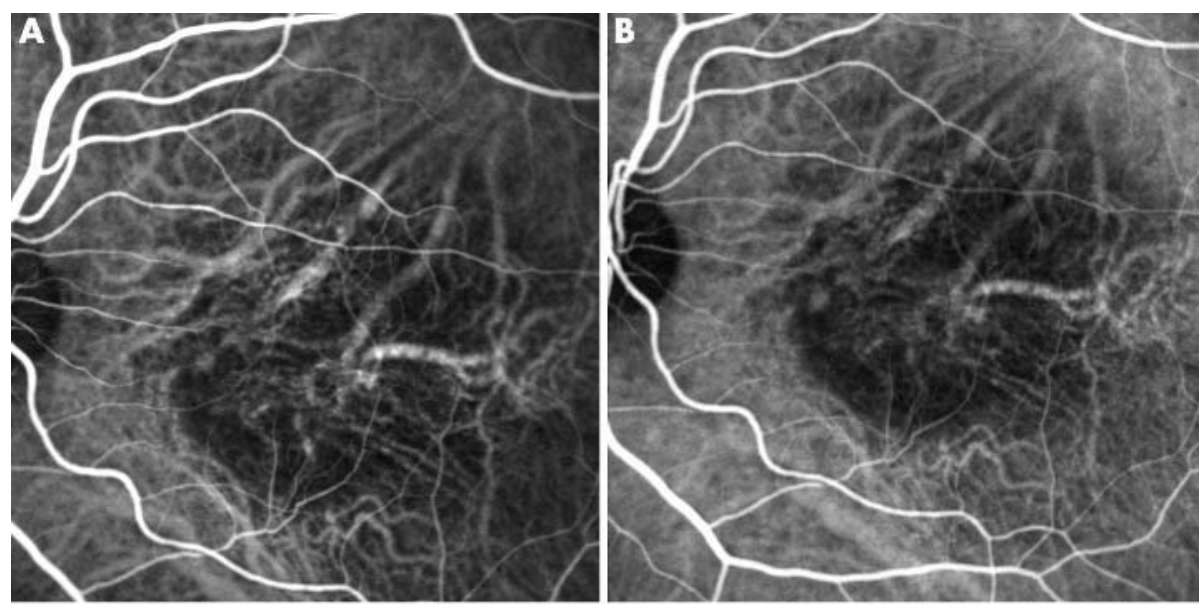

Figure 5 Indocyanine green (ICG) angiography of a 73 year old phakic patient using $5 \mathrm{mg}$ of dye. Only the late phase images show somewhat less contrast. (A) 1 minute, (B) 5 minutes, (C) 15 minutes, (D) 30 minutes.
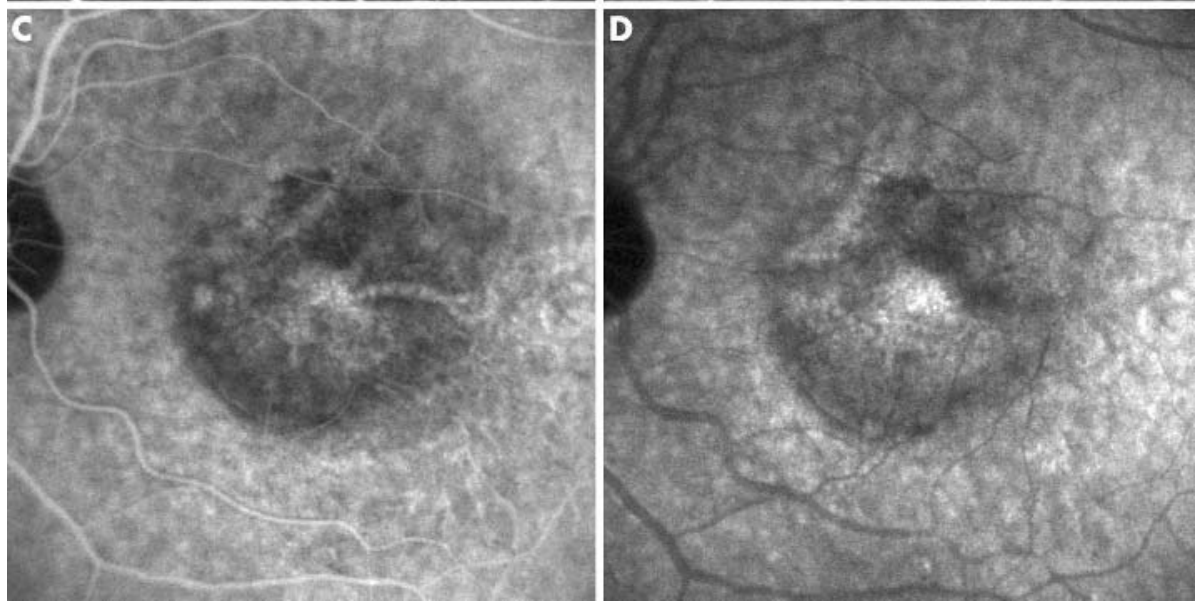

(table 2). Statistical analysis did not reveal a significant difference between different amounts of FL during the early phases (linear by linear association $=0.291$ for 1 minute and 0.114 for 5 minutes) (table 2). At 15 minutes after FL bolus injection, only one image ( $166 \mathrm{mg}$ FL) was classified as "not readable." For all volumes and dye amounts $21 \%$ of FL-A images were classified as "very good" and 58.1\% as "good"; higher amounts of FL led to an overall better classification (linear by linear association $=0.004$ ). At 30 minutes after FL bolus injection, no image obtained with $500 \mathrm{mg}$ fluorescein was classified as "not readable." The rates for "not readable" late phase fluorescein angiograms are given in table 2. Statistical analysis indicated overall better image quality using higher amounts of FL (linear by linear association $=0.002)($ table 2$)($ figs 2 and 3$)$.

For the ICG dye, we performed 45 ICG-As in 39 patients, using identical dye concentrations in different volumes

Table 3 Indocyanine green angiographies and dye amounts used

\begin{tabular}{lll}
\hline $\begin{array}{l}\text { No } \\
(\mathbf{n}=\mathbf{4 5 )}\end{array}$ & $\begin{array}{l}\text { ICG } \\
\text { amount }\end{array}$ & $\begin{array}{l}\text { ICG injected } \\
\text { volume } \\
(\mathbf{5 m} / \mathrm{ml})\end{array}$ \\
\hline 5 & $2.5 \mathrm{mg}$ & $0.50 \mathrm{ml}$ \\
13 & $5 \mathrm{mg}$ & $1.00 \mathrm{ml}$ \\
8 & $10 \mathrm{mg}$ & $2.00 \mathrm{ml}$ \\
8 & $15 \mathrm{mg}$ & $3.00 \mathrm{ml}$ \\
5 & $20 \mathrm{mg}$ & $4.00 \mathrm{ml}$ \\
6 & $25 \mathrm{mg}$ & $5.00 \mathrm{ml}$ \\
\hline
\end{tabular}

(table 3). Of the group, 19 patients were phakic and 20 patients were pseudophakic. Four frames of each ICG-A ( 1,5 , 15, and 30 minutes after injection) were evaluated. A proportion of $71.1 \%$ of images taken 1 minute after injection were rated as "very good" (table 4). At 5 minutes after injection, ICG-A with $2.5 \mathrm{mg}$ and $5 \mathrm{mg}$ of fluorescence dye led to single images with "poor" image quality; in general, images were significantly better with higher amounts of dye (linear by linear association $=0.09$ for 1 minute and 0.05 for 5 minutes) (table 5). The late phase images overall had slightly worse ratings with lower levels of dye (linear by linear association $=0.00$ for 15 minutes and 0.00 for 30 minutes) (table 5). Out of all 15 minute frames, only one image (20\%) taken with $2.5 \mathrm{mg}$ and two images (15.3\%) taken with $5 \mathrm{mg}$ dye were classified as "not readable." Proportions for 30 minutes shots classified as "not readable" were 60\% (three out of five) in the $2.5 \mathrm{mg}$ group and $30.8 \%$ (four out of 13) in the $5 \mathrm{mg}$ group. At higher amounts, none of the images was classified as "not readable" (table 4) (figs l and 4).

\section{DISCUSSION}

With the advent of cSLO, low levels of fluorescence in the human eye can be recorded. Recommendations regarding the amount of dye to be injected for FL-A (500 mg) and ICG-A (25 mg) are based on conventional camera systems that were introduced decades ago. With a stepwise reduction of dye volumes injected while maintaining the same concentrations, the current study indicates that for routine clinical purposes, $166 \mathrm{mg}$ of fluorescein and $5 \mathrm{mg}$ of ICG are sufficient when using a new cSLO system.

The use of only one third of the FL-A and one fifth of the ICG-A conventionally used dye amounts, respectively, allows 


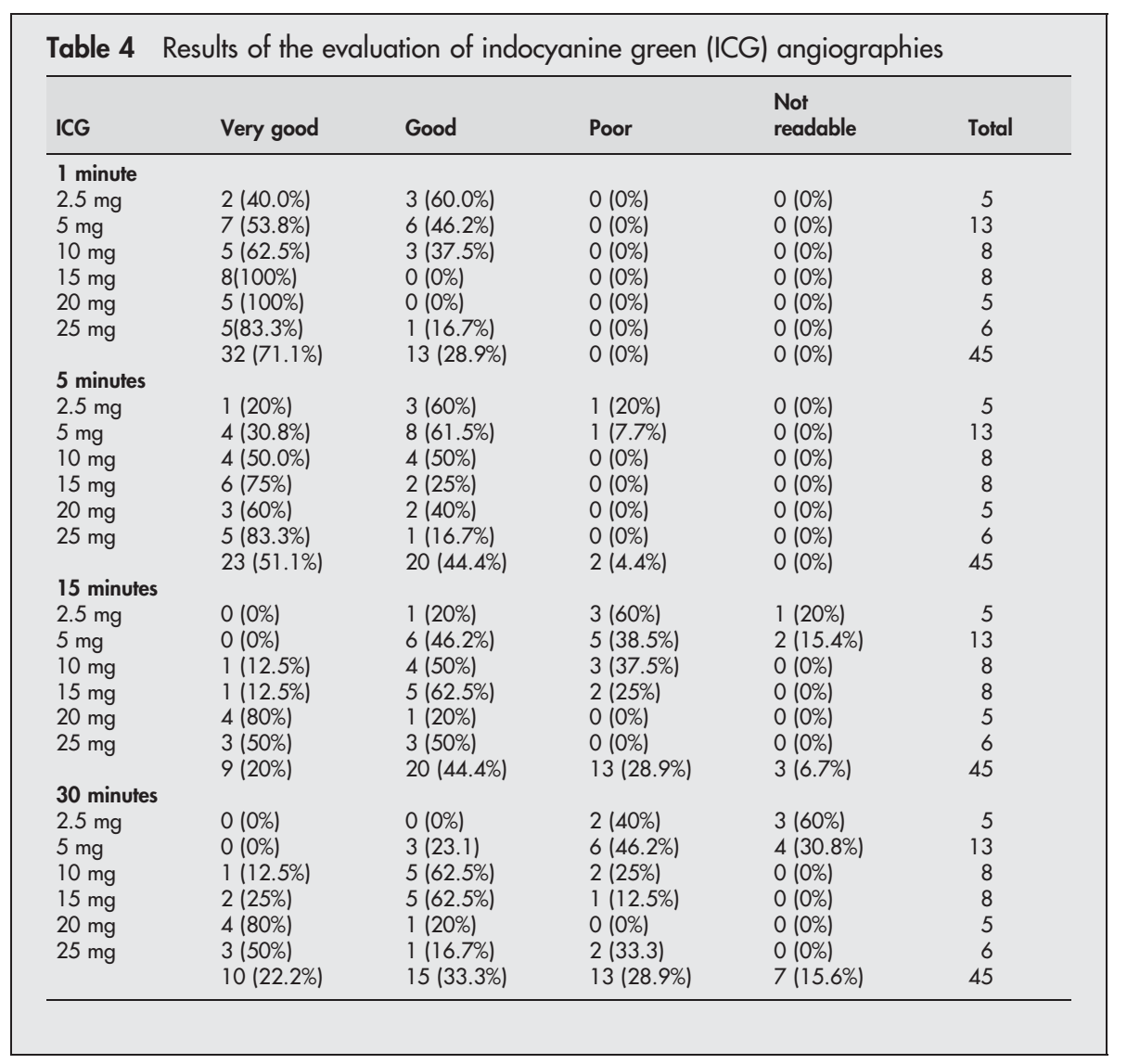

for relevant savings in times of cost constraints for all health systems. These savings would especially apply to high volume medical retina departments. Furthermore, there is evidence to suggest that side effects of fluorescein, such as nausea, are dose dependent, ${ }^{27}$ and it would be expected that using lower dye amounts would reduce the incidence of these side effects. Therefore, it appears prudent to use minimally necessary dye amounts for fluorescence angiography.

The analyses of both FL-A and ICG-A images indicated that image quality diminishes in late phases, especially with a reduction in dye amounts, which was the expected outcome. Lower amounts of dye below the threshold mentioned above would not be sufficient to obtain enough information from the angiographic examinations. Minor reductions in contrast and resolution appear irrelevant for the clinical management of patients in a routine setting. For example, as long as the borders of a classic choroidal neovascularisation (CNV) are clearly delineated in the early phase and leakage of dye is identified in later frames, the physician can determine his or her therapeutic strategy (for example, photodynamic therapy). In addition, other factors may be more important for

\begin{tabular}{l}
$\begin{array}{l}\text { Table } 5 \text { Statistical analysis of ICG-A for evaluation of } \\
\text { the relation between dye amount and image quality using } \\
\text { different amounts of dye }\end{array}$ \\
\hline \begin{tabular}{ll} 
Time & Linear by linear \\
(minutes) & association \\
1 & $\mathbf{1} \mathbf{0 . 0 5}$ significant) \\
\hline 1 & 0.09 \\
15 & 0.05 \\
30 & 0.00 \\
& 0.00
\end{tabular}
\end{tabular}

interpreting angiographic findings than optimal image resolution. ${ }^{29}$

For special purposes-for example, identification of miniscule structures visualised during angiography such as flow in the capillary perifoveal network or recordings for illustrations, the use of conventional dye amounts may be considered to achieve optimal resolution. Again, such use does not appear to be necessary for routine angiographies.

Lower dye amounts can also be used for simultaneous FL$A$ and ICG-A using the CSLO system. We have shown previously that both FL and ICG dye can be mixed in one syringe and injected as bolus with subsequent simultaneous recordings. ${ }^{17}{ }^{30}$

Various limitations have to be considered when interpreting this study. We only investigated patients with various manifestations of AMD; however, we assume that these findings would be comparable in the presence of other retinal pathologies. Furthermore, only patients with relatively clear media were examined. Advanced lens opacities may impair fluorescence image quality by absorption both in the excitation and absorption spectra of the fluorescent dyes. Therefore, lower amounts of dye may be disadvantageous in eyes with advanced cataract, and it may be prudent to use standard amounts under such circumstances. The relatively small number of subjects in each subgroup represents a limitation of the study and needs to be considered when interpreting the data. However, since there was overall relatively little variability within the subgroups, we would assume that larger numbers would in essence not yield other results. Finally, the classification of image quality is obviously a subjective evaluation; however, there is no objective means available to accomplish more accurate ratings.

In summary, this new cSLO (HRA2) allows for detection of low levels of fluorescence. We have shown that it is possible to use amounts of fluorescein and/or ICG dyes for routine 
fluorescence angiography that are lower than those previously used for conventional camera based systems. This finding also allows for relevant savings in expenses.

\section{Authors' affiliations}

A Bindewald, O Stuhrmann, F Roth, S Schmitz-Valckenberg, H-M Helb, A Wegener, N Eter, F G Holz, Department of Ophthalmology, University of Bonn, Ernst-Abbe-Strasse 2, D-53127 Bonn, Germany

Competing interests: none declared

\section{REFERENCES}

1 Rabb MF, Burton TC, Schatz H, et al. Fluorescein angiography of the fundus: a schematic aproach to interpretation. Surv Ophthalmol 1978;22:387-403.

2 Guyer DR, Puliafito CA, Monés JM, et al. Digital indocyanine green angiography in chorioretinal disorders. Ophthalmology 1992:99:287-91.

3 Yannuzzi LA, Slakter JS, Sorenson JA, et al. Digital indocyanine green videoangiography and choroidal neovascularization. Retina 1992; 12:191-223.

4 Scheider A, Kaboth A, Neuhauser L. The detection of subretinal neovascular membranes with indocyanine green and an infrared scanning laser ophthalmoscope. Am J Ophthalmol 1992;113:45-51.

5 Yoneya S, Noyori K. Improved visualization of the choroidal circulation with indocyanine green angiography (letter). Arch Ophthalmol

1993:111:1165-6.

6 Guyer DR, Yannuzzi LA, Slakter JS, et al. Digital indocyanine-green videoangiography of occult choroidal neovascularization. Ophthalmology 1994; 101:1727-35

7 Wolf S, Remky A, Elsner AE, et al. Indocyanine green video angiography in patients with age-related maculopathy-related retinal pigment epithelial detachments. Ger J Ophthalmol 1994;3:224-7

8 Arnold JJ, Quaranta M, Soubrane G, et al. Indocyanine green angiography of drusen. Am J Ophthalmol 1997;124:344-56.

9 Spaide RF. Fluorescein Angiography. In: Spaide RF, ed. Diseases of the retina and vitreous. Philadelphia: WB Saunders Co, 1999:29-38.

10 Tittl MK, Slakter JS, Spaide RF, et al. Indocyanine green videoangiography. In: Spaide RF, ed. Diseases of the retina and vitreous. Philadelphia: WB Saunders, 1999:39-46.

11 Novotny HR, Alvis DL. A method of photographing fluorescence in circulating blood in the human retina. Circulation 1961;24:82-6.

12 Webb RH, Hughes GW, Pomerantzeff O. Flying spot TV ophthalmoscope. Appl Opt 1980;19:2991-7.

13 Webb R, Hughes GW. Scanning laser ophthalmoscope. IEEE Trans Biomed Eng 1981;28:488-92.
14 Webb RH, Hughes GW, Delori FC. Confocal scanning laser ophthalmoscope. Appl Opt 1987;26:1492-9.

15 Holz FG, Bellman C, Staudt S, et al. Fundus autofluorescence and development of geographic atrophy in age-related macular degeneration. Invest Ophthalmol Vis Sci 2001;42:1051-6.

16 Bindewald A, Jorzik JJ, Loesch A, et al. Visualisation of retinal pigment epithelial (RPE) cells in vivo using digital high resolution confocal scanning laser ophthalmoscopy. Am J Ophthalmol 2004;137:556-8.

17 Jorzik JJ, Bindewald A, Dithmar S, et al. Digital simultaneous fluorescein and indocyanine green angiography, autofluorescence and redfree imaging with a solid state laser based confocal SLO. Retina 2005;25:405-16.

18 Mainster MA, Timberlake GT, Webb RH, et al. Scanning laser ophthalmoscopy. Clinical applications. Ophthalmology 1982;89:852-7.

19 Flower RW, Hochheimer BF. A clinical technique and apparatus for simultaneous angiography of the separate retinal and choroidal circulations. Invest Ophthalmol 1973;12:248-61.

20 Bartsch DU, Weinreb RN, Zinser G, et al. Confocal scanning infrared laser ophthalmoscopy for indocyanine green angiography. Am J Ophthalmol 1995; 120:642-51.

21 Dithmar S, Holz FG, Burk ROW, et al. [Confocal scanning laser indocyanine green angiography with the Heidelberg retinal angiograph.] (in German) Klin Monatsbl Augenheilkd 1995;207:11-16.

22 Freeman WR, Bartsch DU, Mueller AJ, et al. Simultaneous indocyanine green and fluorescein angiography using a confocal scanning laser ophthalmoscope. Arch Ophthalmol 1998;116:455-63.

23 Holz FG, Bellmann C, Rohrschneider K, et al. Simultaneous confocal scanning laser fluorescein and indocyanine green angiography. Am J Ophthalmol 1998; 125:227-36

24 Plesch A, Chapero V, Bille J, et al. [Laser scanning ophthalmoscopy.] Fortschr Ophthalmol 1986:83:530-1.

25 Holz FG, Bellmann C, Margaritidis $M$, et al. Patterns of increased in vivo fundus autofluorescence in the junctional zone of geographic atrophy of the retinal pigment epithelium associated with age-related macular degeneration. Graefes Arch Clin Exp Ophthalmol 1999;237:145-52.

26 American National Standards Institute. American national standard for the safe use of lasers: ANSI Z136.1. Orlando, FL: Laser Institute of America, 2000.

27 Yannuzzi LA, Rohrer KT, Tindel $\sqcup$, et al. Fluorescein angiography complication survey. Ophthalmology 1986:93:611-17.

28 World Medical Association. Revising the Declaration of Helsinki. Bull Med Ethics 2000;158:9-11.

29 Holz FG, Jorzik J, Schutt F, et al. Agreement among ophthalmologists in evaluating fluorescein angiograms in patients with neovascular age-related macular degeneration for photodynamic therapy eligibility (FLAP-study). Ophthalmology 2003;1 10:400-5.

30 Holz FG, Bellmann C, Dithmar S, et al. Simultaneous fluorescein and indocyanine green angiography with a confocal laser ophthalmoscope. Ophthalmologe 1997;94:348-53. 